\title{
Effects of organic and inorganic compounds of diesel exhaust particles on the mucociliary epithelium: An experimental study on the frog palate preparation
}

\author{
Sergio Henrique Kiemle Trindade ${ }^{\mathrm{a}, \mathrm{b}}$, Robson Seriani ${ }^{\mathrm{a}, \mathrm{c}, *}$, Geraldo Lorenzi-Filho $^{\mathrm{a}, \mathrm{d}}$, \\ João Ferreira de Mello Júnior ${ }^{\mathrm{e}}$, Luiz Ubirajara Sennes ${ }^{\mathrm{d}}$, Paulo Hilário Nascimento Saldiva ${ }^{\mathrm{a}}$, \\ Mariângela Macchione ${ }^{\mathrm{a}}$ \\ ${ }^{a}$ Laboratory of Experimental Air Pollution, Faculdade de Medicina, Universidade de São Paulo, São Paulo, SP, Brazil \\ b Otorhinolaryngology - Head and Neck Surgery Departament, Botucatu Medical School, UNESP - São Paulo State University, Botucatu, SP, Brazil \\ ${ }^{\mathrm{c}}$ Departament of Biological Sciences - Faculdade das Américas, Unidade Paulista, São Paulo, SP, Brazil \\ d Sleep Laboratory, Pulmonary Division, Heart Institute (InCor), Hospital das Clínicas, Faculdade de Medicina, Universidade de São Paulo, São Paulo, SP, Brazil \\ e Otorhinolaryngology Division, Hospital das Clínicas, Faculdade de Medicina, Universidade de São Paulo, São Paulo, SP, Brazil
}

\section{A R T I C L E I N F O}

\section{Keywords:}

Air pollution

Vehicle emissions

Epithelium

Cilia

Particulate matter

\begin{abstract}
A B S T R A C T
The toxic actions of acute exposition to different diesel exhaust particles (DEPA) fractions on the mucociliary epithelium are not yet fully understood due to different concentrations of organic and inorganic elements. These chemicals elements produce damage to the respiratory epithelium and exacerbate pre-existent diseases. In our study we showed these differences in two experimental studies. Study I (dose-response curve - DRCS): Forty frogpalates were exposed to the following dilutions: frog ringer, intact DEPA diluted in frog-ringer at $3 \mathrm{mg} / \mathrm{L}, 6 \mathrm{mg} / \mathrm{L}$ and $12 \mathrm{mg} / \mathrm{L}$. Study II (DEPF) (DEPA fractions diluted at $12 \mathrm{mg} / \mathrm{L}$ ): Fifty palates - Frog ringer, intact DEPA, DEPA treated with hexane, nitric acid and methanol. Variables analyzed: relative time of mucociliary transport (MCT), ciliary beating frequency (CBF) and morphometric analysis for mucin profile (neutral/acid) and vacuolization. The Results of DRCS: Group DEPA-12 mg/L presented a significant increase in the MCT ( $<<0.05)$, proportional volume of acid mucus $(\mathrm{p}<0.05)$ and decreased proportional volume of neutral mucus and vacuoles $(\mathrm{p}<0.05)$. In relation of DEPF: A significant increase in the MCT associated to a decrease in the proportional volume of neutral mucus was founded in nitric acid group. In addition, a significant increase in the proportional volume of acid mucus was found in methanol group. We concluded that: 1) Increasing concentrations of intact DEPA can progressively increase MCT and promote an acidification of intra-epithelial mucins associated to a depletion of neutral mucus. 2) Intact DEPA seem to act as secretagogue substance, promoting mucus extrusion and consequently reducing epithelial thickness. 3) Organic fraction of low polarity seems to play a pivotal role on the acute toxicity to the mucociliary epithelium, by promoting a significant increase in the MCT associated to changes in the chemical profile of the intracellular mucins.
\end{abstract}

\section{Introduction}

Air pollution in major urban centers is recognized as a source of potential health problems. Epidemiological studies have shown a clear association between increasing concentration of atmospheric pollutants, especially diesel exhaust particles (DEPA), with respiratory and cardiac morbidity and mortality in the general population (Dockery et al., 1993; Souza et al., 1998; Martins et al., 2002). Two million premature deaths worldwide occur each year due to air pollution
(Filleul et al., 2005; Forastiere et al., 2005; Goldberg et al., 2006). Among the major agents responsible for these phenomena are dieselpowered vehicles. In addition, Miraglia et al. (2005) showed that health costs due to air pollution among children and seniors in São Paulo are US\$3,222,676.00 per year.

Urban Particulate Matter has deleterious actions on upper and lower airways exerting its toxic actions mainly on the mucociliary epithelium (Macchione et al.,1995,1999; Yoshizaki et al., 2010). The mucociliary defense system is responsible for removing particulates and pathogens

\footnotetext{
Abbreviations: DEPA, diesel exhaust particles; MCT, mucociliary transport; PM, particulate matter

* Corresponding author at: Laboratory of Experimental Air Pollution, Faculdade de Medicina, Universidade de São Paulo, São Paulo, SP, Brazil.

E-mail address: robsonseriani@yahoo.com.br (R. Seriani).
} 
that are over the mucus lining the airways. DEPA with aerodynamic diameter around 10 micra (coarse particles - $\mathrm{PM}_{10}$ ) become trapped on the mucus lining upper airway epithelium. These particles probably interact with the mucociliary system playing an important role in mucociliary clearance impairment (Macchione et al., 1999), which in turn is closely associated with the development of respiratory symptoms.

In vitro studies showed that human cells and tissues and experimental models when exposed to DEPA could produce reactive oxygen species, suggesting that one of the major mechanisms of cell damage is mediated by oxidative stress (Hiura et al., 1999; Li et al., 2002; Seriani et al., 2016). Mucus acidification, elicited by oxidative injury, results in changes in physicochemical properties of mucins, leading to increased mucus viscosity and consequently mucociliary impairment (Giddens and Fairchild, 1972; Holma et al., 1977; Holma, 1989; Seriani et al., 2014).

Theoretically DEPA can be subdivided in two fractions: 1) inorganic fraction, basically composed by a carbon core and adsorbed over this nucleus, sulphates and metals; 2) Organic fraction: mainly composed by hidrocarbons derived from the fuel and lubricating oil. Seriani et al. (2015a) show that the effects of different DEPA fractions on the mucociliary epithelium in Balb/C. However, which fraction is the most toxic to the mucociliary epithelium and the mechanisms responsible for the impairment of the mucociliary transport still require further elucidation.

In this study, at the Dose-Response Curve Study (DRCS), we aimed at determine a concentration of intact DEPA that was able to generate an acute damage to the mucociliary epithelium. To this end, we performed a series of experiments and constructed a dose-response curve to verify the effects of increasing concentrations of intact DEPA on the frog palate preparation $(0,3,6$ and $12 \mathrm{mg} / \mathrm{L})$, by analyzing mucociliary transport and morphometric parameters, including proportional volume of acid and neutral intra-epithelial mucus, mixed colored mucus, cilia on the surface of epithelial cells, vacuoles, cell nuclei and interstice. Lastly, epithelial thickness was measured in order to evaluate the degree of mucus extrusion. In Study II (Diesel Exhaust Particles Fractions - DEPF), we hypothesized that DEPA fractions could have different patterns of mucociliary epithelium damage. After the determination of a deleterious concentration of intact DEPA, we performed a new series of experiments, with a constant concentration of DEPA, treated with hexane (solvent that reduces the amount of organic compounds of low polarity), methanol (solvent that reduces the amount of organic compounds of intermediate polarity) and nitric acid (solvent that reduces the amount of inorganic compounds), in order to evaluate which fraction has a central role in mucociliary activity impairment. In Study II we included the evaluation of ciliary beating frequency after the measurements of MCT time.

\section{Methods}

\subsection{Particle collection}

DEPA used in the present study were the same collected Yoshizaki et al. (2010). Samples were collected by a particle trap device adapted to the exhaust pipe of a bus from the public transportation fleet of São Paulo, equipped with a Mercedes Benz MB1620, 210-hp engine, without electronic control of fuel injection, running with diesel containing $500 \mathrm{ppm}$ sulfur. This particular type of bus was chosen because it is the most frequent one operating in Sao Paulo, based on the information given by the municipality. Briefly, a mesh made of stainless steel was inserted into the exhaust pipe line of the bus. Diesel particles were collected after one day of routine operation of the bus and stored for toxicological studies. The study was approved by the local Research Oversight Committee (protocol number 330/06).

\subsection{Particle composition analysis}

Intact particles were analyzed for metals and organic content. The concentration of $\mathrm{Ni}, \mathrm{S}, \mathrm{Fe}, \mathrm{V}, \mathrm{Pb}, \mathrm{Cd}, \mathrm{Cr}$, and $\mathrm{Cu}$ was determined by energy-dispersive energy X-ray fluorescence spectrometer (EDX 700HS, Shimatzu Corporation Analytical Instruments Division, Kyoto, Japan). Polycyclic aromatic hydrocarbons (PAHs) were analyzed by high performance liquid chromathography. The concentrations of the following PAHs were determined: benz $[a]$ anthracene, benzo $[b]$ fluoranthene, benzo $[k]$ fluoranthene, benzo $[a]$ pyrene, dibenz[ah]anthracene, and indeno[123-cd]pyrene.

\subsection{Particle treatment}

Total collected mass of particles (12 g) (DEPA crude) was submitted to different extraction protocols as follows:

Acidic extraction: Particles were immersed in $160 \mathrm{ml} \mathrm{HNO} 3$ at $65 \%$ $(\mathrm{pH} 3)$ to remove any metals present, sonicated for $60 \mathrm{~min}$, and left to rest for $24 \mathrm{~h}$. Thereafter,

the solution was centrifuged for $20 \mathrm{~min}$ at $604 \times g$ at $5{ }^{\circ} \mathrm{C}$ for $10 \mathrm{~min}$ and at $6708 \times g$

at $10 \circ \mathrm{C}$. The supernatant was collected and particles were dried at $57^{\circ} \mathrm{C}$ in a fume hood for $48 \mathrm{~h}$ before use.

Extraction with two solvents with different polarities: Particles were immersed either in $160 \mathrm{ml}$ methanol (DEPA/MET) to remove organic compounds with intermediary polarity or in hexane (DEPA/HEX) (P.A. grade) to remove organic compounds with low polarity, sonicated for $60 \mathrm{~min}$, and left to rest for $24 \mathrm{~h}$. Solutions were centrifuged for $15 \mathrm{~min}$ at $1811 \times g$ at $10^{\circ} \mathrm{C}$. The supernatant was discarded and the precipitate was stored in a vacuum dissector for $15 \mathrm{~h}$. The levels of PAH (ng/g) and metal content ( $\mathrm{ppm})$ in intact diesel particles and after the extraction procedures were then measured (Laks et al., 2008).

The exact composition of inorganic and organic compounds of DEPA and their fractions used in the present study was previouslys described in details in Laks et al. (2008). This same DEPA was used by Yoshizaki et al. (2010), Seriani et al. (2014) and Seriani et al. (2015b).

\subsection{The frog-palate preparation}

The frog palate is a simple and efficient preparation to study mucociliary transport (MCT). The palate is lined with a pseudostratified epithelium composed of both ciliated and mucus-secreting cells, which is similar to the epithelium in human conductive airways (Rubin et al., 1990b). Mature bullfrogs (Lithobates catesbeianus) weighing approximately $100 \mathrm{~g}$ were obtained from Mogi das Cruzes city vivarium. In our laboratory, the animals received a balanced diet and water ad libitum, according to routine veterinary procedures, until their sacrifice. Using hypothermia as anesthesia, the frogs were rapidly decapitated, their jaws were disarticulated, and the palates were removed by cutting through from the junction of the posterior pharynx and esophagus to the skin of the back (Carvalho-Oliveira et al., 2005). The excised palates were placed on a piece of gauze saturated with Ringer. The frog palate was kept in a refrigerator at $4{ }^{\circ} \mathrm{C}$ for 2 days. It was covered with plastic wrap in a humidified chamber to allow for natural depletion of the palate mucus. On day 2 mucus samples were collected from the posterior edge of the palate with a needle. The samples were immediately immersed in mineral oil to prevent dehydration, according to the procedures described by Rubin et al. (1990a). All of the experiments were performed between days 2 and 5 after frog palate removal. Under these experimental conditions the mucus layer is depleted but the ciliary activity is maintained (Macchione et al., 1995).

\subsection{Mucociliary transport (MCT) analysis}

For testing how a mucus sample reacts when transported by the cilia, a small frog mucus drop was positioned on the beginning of the 
surface of the palate, and the time elapsed for the displacement of the sample in a pre-determined distance $(6 \mathrm{~mm})$ was measured, with the aid of a sterioscopic microscope equipped with a reticulated eyepiece. MCT was measured at time zero, $30 \mathrm{~min}, 60 \mathrm{~min}$ and $90 \mathrm{~min}$ after the palate submersion into the dilutions with different concentrations and fractions of DEPA. During the measurements the palate was kept in an acrylic chamber with an atmosphere with $100 \%$ of humidity provided by an ultrasonic nebulizer with frog-ringer solution. At least five measurements were performed in each test to confirm data reliability. MCT was expressed in terms of relative time. Briefly, the mean value of a determined measurement was divided by the mean value corresponding to time zero for the same group. The results were expressed in terms of proportion (relative time).

\subsection{Ciliary Beating Frequency (CBF)}

CBF was measured by a modification of the videoscopic technique described by Braga et al. (1973). Briefly, a group of cilia was focused with the aid of an optical microscope $(10 \times$ objective, $10 \times$ ocular $)$, connected to a videocamera. A stroboscopic light was used in this setting to illuminate de epithelium surface and consequently promote cyclic reflections of the incident light. At a certain angle of cilia stroke, cilia reflect the light into the microscope, and the area of that cilia group appears as a light spot. When the stroboscopic light frequency reaches the same frequency of the ciliary beating, the whole epithelium seems to stop moving. At this point we have the measurement of the ciliary beating frequency (Macchione et al., 1999).

\subsection{Histological analysis}

After the end of the exposure, the frog palate epithelium was prepared for histological analysis. A fragment of epithelium around $1.0 \mathrm{~cm}^{2}$ was immersed in $4 \%$ neutral buffered formalin. Five-micrometer-thick sections were taken. Sections were stained with a combination of Schiff's periodic acid and Alcian blue (PAS/AB) at a pH of 2.5. With this technique, neutral and acidic glycoproteins are stained in red and blue, respectively (Prent $\varnothing, 2009$ ).

Using a Leica DMR microscope coupled with a photographic camera Zeiss Axio Cam MRc5, the microscopic image was digitalized in highresolution, at 400X magnification. Ten non-consecutive pictures were taken from the epithelium, and mean values of each parameter were analyzed. Different structures of the mucociliary epithelium of the frog palate were quantified using conventional morphometry, with the aid of the program Image pro-plus for PC. Parameters analyzed were proportional volume of acid, neutral and mixed mucus, cilia, vacuoles, cell nuclei and interstice and epithelial thickness.

Volume proportion was determined by point counting. Briefly, the number of points matching each type of structure of the epithelium was counted in the 10 fields of each animal. The sum of these values was divided by the number of pictures taken in each animal, given a single mean value per animal. Then the mean value of the total number of points was calculated for each animal.

Proportional volume (PV) of the structures of interest was calculated by the equation: $\mathrm{PV}=\mathrm{PMI} / \mathrm{TP}$, where $\mathrm{PMI}$ is the mean number of points matching structures of interest, and TP is the mean total number of points hitting the epithelium. Volume was expressed in terms of proportion.

\subsection{Exposure protocol}

Forty palates, divided into four groups, were used in the Study I. Palates were exposed to intact DEPA at $3 \mathrm{mg} / \mathrm{L}, 6 \mathrm{mg} / \mathrm{L}, 12 \mathrm{mg} / \mathrm{L}$ and to frog ringer for control purposes. Measurements of mucociliary transport time (MCT) were made before and after immersion of the palates with the different solutions at time: zero minutes (T0), thirty minutes (Т30), sixty minutes (T60) and ninety minutes (T90). In Study II, after the determination of the most deleterious concentration, fifty palates were also divided into five groups and exposed to the following solutions with $12 \mathrm{mg} / \mathrm{L}$ of DEPA fractions: Frog ringer (control group), intact DEPA, DEPA treated with hexane, nitric acid and methanol. The experiments in Study II were blinded and the order of the different solutions exposure was determined by raffle.

\section{Statistical analysis}

In Study I, analysis of variance was performed to compare the results of MCT for repeated measures taking into account two factors: exposure time and concentration. In Study II the factors analyzed were time exposure and type of dilution. To assess normality, the Kolmogorov-Smirnov test was used. Data with normal distribution were assessed by two-way ANOVA and with non-normal distribution, by the Kruskal Wallis test. Paired comparisons between groups were performed by Tukey test for normally distributed data and non-normally distributed data were compared by Dunn's method. On morphometry, analysis of variance for repeated measures was preformed taking into account one factor: the pollutant concentration or the pollutant fraction. To assess normality, the Kolmogorov-Smirnov test was used. Data with normal distribution were assessed by one-way ANOVA and the data with non-normal distribution, by the Kruskal Wallis test. Paired comparisons between groups were performed by the Holm-Sidak method for data with normal distribution and for non- normally distributed data were compared by Dunn's method. The level of significance was set at $5 \%$.

\section{Results}

Fig. 1 shows mean values of DRCS (Study I) mucociliary transport, expressed as relative time. Group $12 \mathrm{mg} / \mathrm{L}$ presented mean values of relative time higher than the control, $3 \mathrm{mg} / \mathrm{L}$ and $6 \mathrm{mg} / \mathrm{L}$ groups $(\mathrm{p}<0.05)$. Group $6 \mathrm{mg} / \mathrm{L}$ presented mean values higher than control and $3 \mathrm{mg} / \mathrm{L}$ groups $(\mathrm{p}<0.05)$.

Morphometric analysis of the frog palate epithelium showed that palates exposed to group $12 \mathrm{mg} / \mathrm{L}$ presented a significantly higher proportional volume of acid mucus than control, $3 \mathrm{mg} / \mathrm{L}$ and $6 \mathrm{mg} / \mathrm{L}$ groups ( $\mathrm{p}<0.05$ ) (Fig. 2). The palates exposed to $12 \mathrm{mg} / \mathrm{L}$ also presented significantly lower proportional volume of neutral mucus (a) and vacuoles (b) than the control group ( $\mathrm{p}<0.05)$ (Fig. 3).

The analysis of epithelial thickness showed that group $6 \mathrm{mg} / \mathrm{L}$ presented significantly lower values than the control group $(\mathrm{p}<0.05)$. The graphical representation of mean values of epithelial thickness and distribution in percentiles are shown in Fig. 4. No significant differences between groups were seen for proportional volume of mixed mucus, cilia, nuclei and interstice ( $\mathrm{p}>0.05)$.

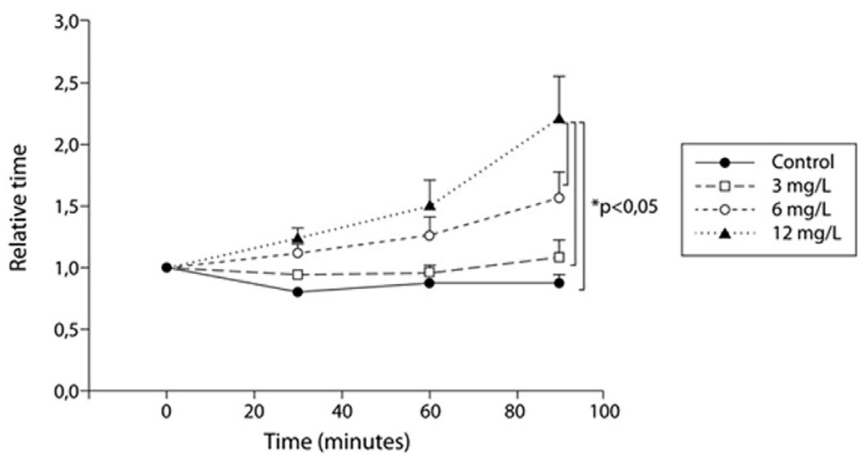

Fig. 1. Results of mucociliary transport time after immersion of the palate in the following dilutions: frog ringer (control group) and intact DEP at $3 \mathrm{mg} / \mathrm{L}, 6 \mathrm{mg} / \mathrm{L}$ and $12 \mathrm{mg} / \mathrm{L}$, at time zero, thirty, sixty and ninety minutes. Comparisons between groups linked by brackets revealed significant differences $\left({ }^{*} \mathrm{p}<0.05\right)$. Number of animals evaluated in each group $=10$. 


\section{Acid mucus analysis}

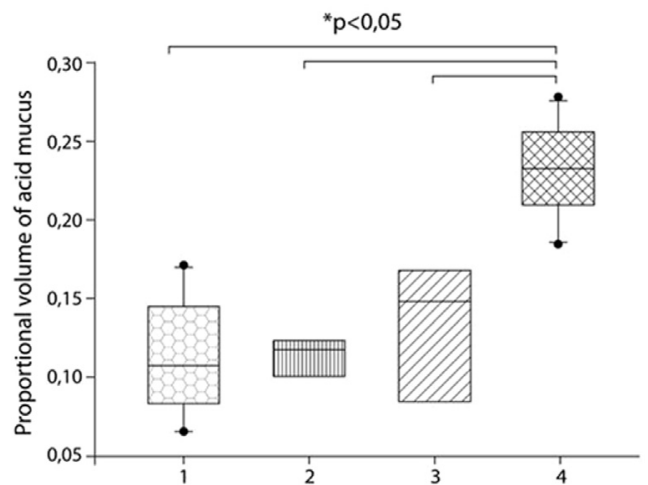

Fig. 2. Proportional volume of acid mucus assessed by histological analysis after immersion of the palate in the following dilutions: frog ringer (control group) and intact $\mathrm{DEP}$ at $3 \mathrm{mg} / \mathrm{L}, 6 \mathrm{mg} / \mathrm{L}$ and $12 \mathrm{mg} / \mathrm{L}$. The Y-axis represents the proportional volume of acid mucus. The middle line of the box-plot represents the $50 \%$ percentile. The bottom line represents the $25 \%$ percentile and upper line the $75 \%$ percentile. The black circles represent the "outliers". Comparisons between groups linked by brackets revealed significant differences ( $\mathrm{p} p<0.05$ ). Number of animals evaluated in each group $=10$.

\section{(a) Neutral mucus analysis}
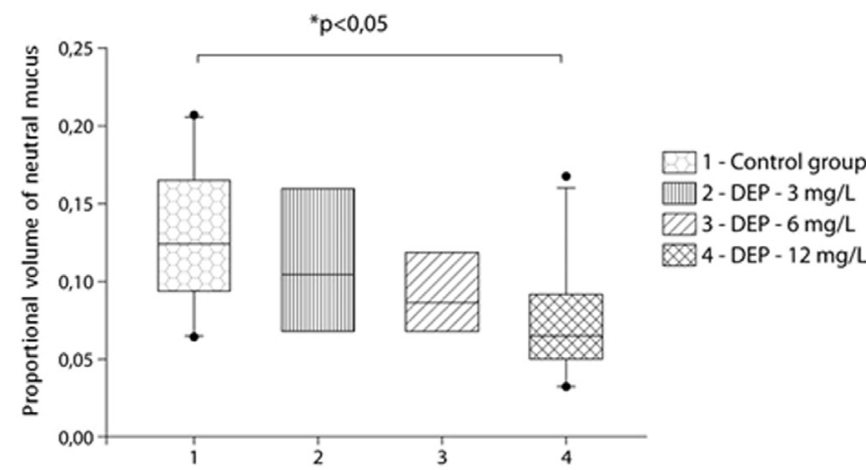

4 - DEP - $12 \mathrm{mg} / \mathrm{l}$

\section{(b) Vacuoles analysis}
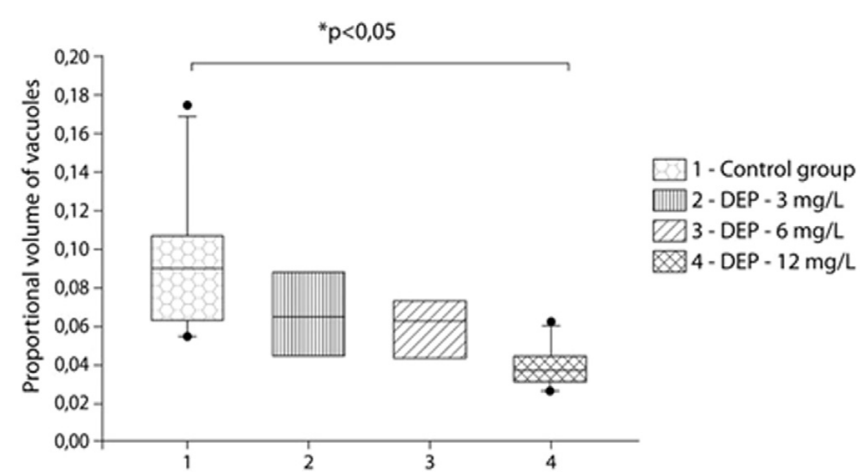

Fig. 3. Proportional volume of neutral mucus (a) and vacuoles (b) assessed by histological analysis after immersion of the palate in the following dilutions: frog ringer (control group) and intact DEP at $3 \mathrm{mg} / \mathrm{L}, 6 \mathrm{mg} / \mathrm{L}$ and $12 \mathrm{mg} / \mathrm{L}$. The Y-axis represents the proportional volume of neutral mucus. The middle line of the box-plot represents the $50 \%$ percentile. The bottom line represents the $25 \%$ percentile and upper line the $75 \%$ percentile The black circles represent the "outliers". Comparisons between groups linked by brackets revealed significant differences ( $\mathrm{p} p<0.05)$. Number of animals evaluated in each group $=10$

In Fig. 5, mean values of Study II (DEPF), MCT relative time are depicted. Nitric acid group presented higher mean values of MCT relative time when compared to intact DEPA group ( $<<0.05)$. Ciliary beating frequency analysis did not present significant differences among groups.

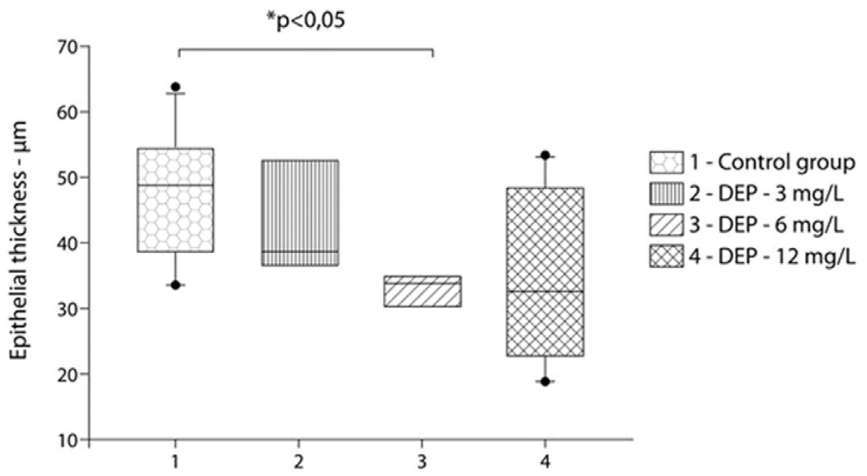

Fig. 4. Epithelial thickness, measured from the apex of ciliated cells to the basal membrane, on histological analysis, after immersion of the palate in the following dilutions: frog ringer (control group) and intact DEP at $3 \mathrm{mg} / \mathrm{L}, 6 \mathrm{mg} / \mathrm{L}$ and $12 \mathrm{mg} / \mathrm{L}$. The Y-axis represents the epithelial thickness. The line in the middle of the box-plot represents the $50 \%$ percentile. The bottom line of box-plot represents the $25 \%$ percentile and the upper line the $75 \%$ percentile. The black circles represent the "outliers". Comparisons between groups linked by brackets revealed significant differences $(* \mathrm{p}<0.05)$. Number of animals evaluated in each group $=10$.

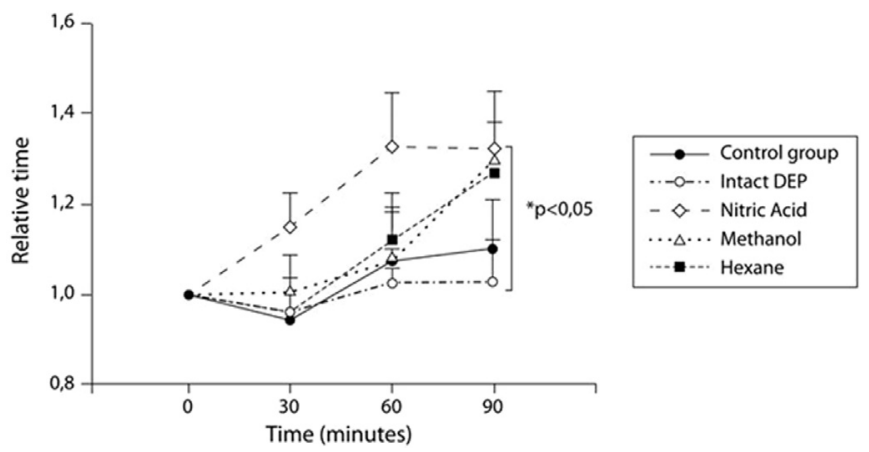

Fig. 5. Changes of MCT relative time after immersion of the palate in the following dilutions: frog ringer (control group) and intact DEP, nitric acid, methanol and hexane, at time zero, thirty, sixty and ninety minutes. Comparisons between groups linked by brackets revealed significant differences (*p $<0.05$ ). Number of animals evaluated in each group $=10$.

In Study II (DEPF) histological analysis results, methanol group presented a higher proportional volume of acid mucus (a) than control group ( $<<0.05)$. Nitric acid group presented a lower proportional volume of neutral mucus (b) than control and hexane groups ( $\mathrm{p}<0.05)$ (Fig. 6).

The analysis of the proportional volume of mixed colored mucus (a) showed that nitric acid group presented higher values than intact DEPA group $(\mathrm{p}<0.05)$, and in the analysis of the vacuoles (b) proportional volume, methanol group presented lower values than intact DEPA group ( $\mathrm{p}<0.05$ ) (Fig. 7). No significant differences between groups were seen for proportional volume of cilia, nuclei and interstice and epithelial thickness ( $\mathrm{p}>0.05)$.

\section{Discussion}

Our study contributes to the literature by evaluating the response of an animal model of mucociliary epithelium to several concentrations of intact DEPA and to different fractions of DEPA. The main findings of the DRCS study I were: mucociliary transport time analysis showed that the harmful potential of intact DEPA gradually increases in progressively rising concentrations.

The DRCS - Study I results are consistent with those found by Macchione et al. (1999), who also noted a significant increase in MCT time on the frog palate preparation after the exposure to urban particulate matter for $120 \mathrm{~min}$. Histological analysis confirmed the harmful potential of DEPA, as the $12 \mathrm{mg} / \mathrm{L}$ group presented a significantly 


\section{(a) Acid mucus analysis}

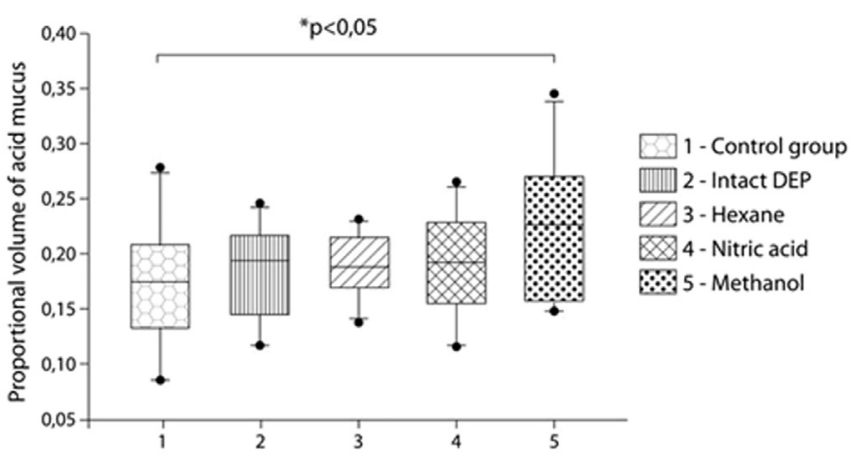

(b) Neutral mucus analysis

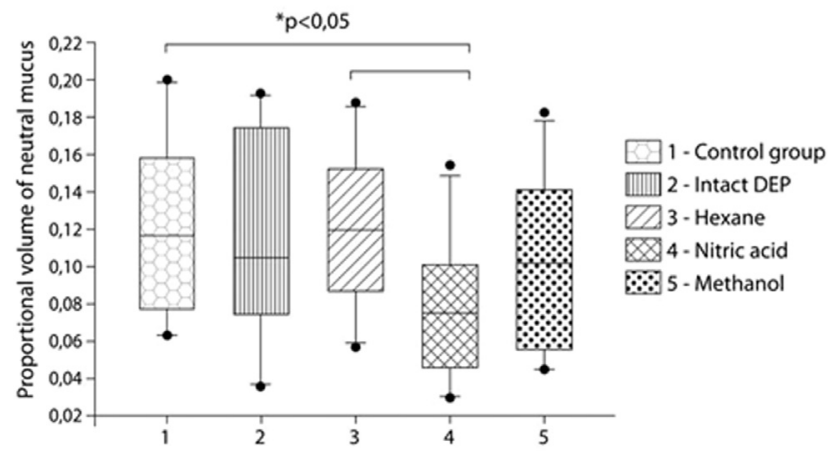

Fig. 6. Proportional volume of acid (a) and neutral (b) mucus assessed by histological analysis after immersion of the palate in the following dilutions: frog ringer (control group) and intact DEP, nitric acid, methanol and hexane. The Y-axis represents the proportional volume of acid mucus. The middle line of the box-plot represents the $50 \%$ percentile. The bottom line represents the $25 \%$ percentile and upper line the $75 \%$ percentile. The black circles represent the "outliers". Comparisons between groups linked by brackets revealed significant differences (*p $<0.05$ ). Number of animals evaluated in each group $=10$.

higher ( $\mathrm{p}<0.001$ ) proportional volume of acid mucus than control, $3 \mathrm{mg} / \mathrm{L}$ and $6 \mathrm{mg} / \mathrm{L}$ groups. Sub-chronic and chronic exposure studies, such as those designed by Lemos et al. (1994), Pires-Neto et al. (2006) and Yoshizaki et al. (2010) also showed a higher concentration of acid mucus in the nasal epithelium of rodents exposed to urban PM and to DEPA.

Our study showed that the proportional rising volume of acid mucus according DEPA-concentration elevation confirmed the hypothesis that the greater the epithelial aggression the greater concentration of acid mucus will be found (Kato and Kagawa, 2003).

Mucus acidification, enabled by changes in mucins physicochemical properties, can lead to cell edema and increased mucus viscosity, what can disrupt mucociliary system integrity and consequently elicit changes in the defense mechanisms of the respiratory epithelium (Giddens and Fairchild, 1972; Holma et al., 1977; Holma, 1989; Daviskas and Anderson, 2006; Li et al., 2007).

We have shown a gradual decrease in mean epithelial thickness with the exposure to increasing concentrations of DEPA. These results can be explained by a possible extrusion of goblet cells mucus granules, as a nonspecific acute defense mechanism of the mucociliary epithelium. Hyperplasia of the frog palate mucociliary epithelium was not possible because it is an "ex vivo" preparation, and hypertrophy could not happen as it requires biosynthesis of mucin that takes 6-24 h (Neutra and Forstner, 1987; Rose and Voynow, 2006). Only $6 \mathrm{mg} / \mathrm{L}$ group showed significantly lower values of epithelial thickness than control group. The $12 \mathrm{mg} / \mathrm{L}$ group, despite having lower median values than $6 \mathrm{mg} / \mathrm{L}$ group, presented higher variance and some "outliers", making (a) Mixed mucus analysis

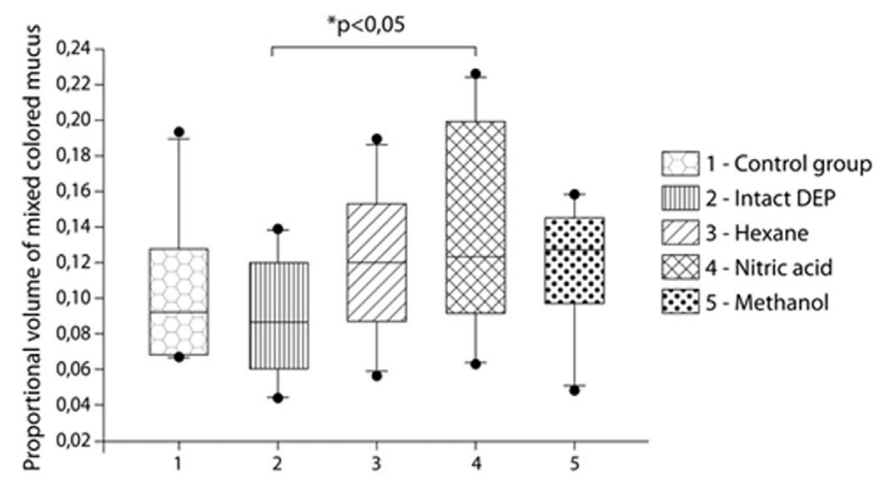

(b) Vacuoles analysis

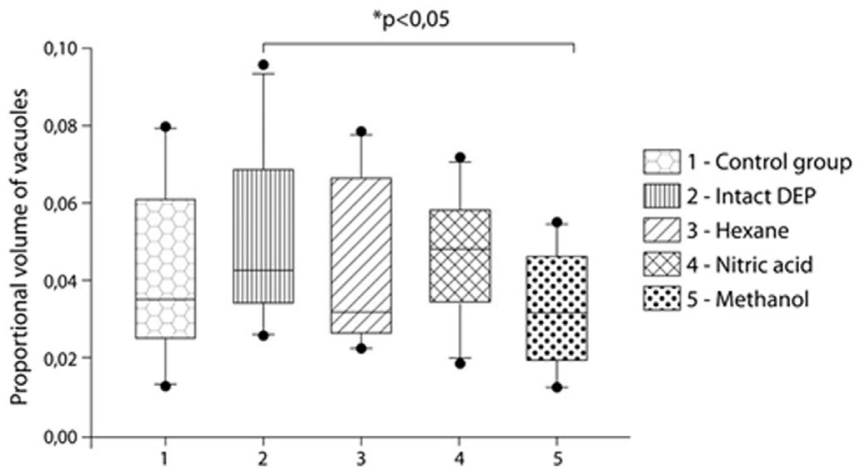

Fig. 7. Proportional volume of mixed colored mucus (a) and vacuoles (b) assessed by histological analysis after immersion of the palate in the following dilutions: frog ringer (control group) and intact DEP, nitric acid, methanol and hexane. The Y-axis represents the proportional volume of acid mucus. The middle line of the box-plot represents the $50 \%$ percentile. The bottom line represents the $25 \%$ percentile and upper line the $75 \%$ percentile. The black circles represent the "outliers". Comparisons between groups linked by brackets revealed significant differences $(* \mathrm{p}<0.05)$. Number of animals evaluated in each group $=10$.

the differences not significant in the comparison with the control group. Regarding neutral mucus and vacuoles analysis, the group exposed to $12 \mathrm{mg} / \mathrm{L}$ presented the lowest proportional volume of these parameters, confirming the harmful potential of this concentration. Macchione et al. (1999) also demonstrated that frog palates exposed to urban PM presented a depletion of their intraepithelial neutral mucus.

The analysis of the proportional volume of cilia revealed no significant differences between groups, demonstrating that the acute exposure of the frog palate to high concentrations is not able to significantly reduce the number of cilia on the surface of the ciliated cells, unlike the previous studies of our group (Lemos et al., 1994) who found a decreased number of cilia in the surface of the ciliated cells, in rats chronically exposed to urban pollution. That might be due to differences in the studies design (acute vs. chronic exposition).

The main findings of DEPF - Study II were: In the MCT time analysis, mean values of nitric acid were significant higher than the intact DEPA group. This finding reinforces the idea that organic compounds play a central role in the acute toxicity to the ciliated epithelium, as nitric acid exposure promotes a relative increase in the total amount of organic compound in treated DEPA (Laks et al., 2008).

Ciliary beating frequency analysis did not show significant differences among groups. Macchione et al. (1999) found similar results when evaluated MCT time of frog palates exposed to urban PM for $120 \mathrm{~min}$. This finding suggests that despite the increase in MCT relative time, ciliary beating frequency could not vary significantly. Histological findings of DEPF- Study II corroborates this idea, as we found 
significant alterations in the chemical profile of the intracellular mucins, preceding alterations in the MCT relative time and ciliary beating frequency.

Results regarding histological analysis, strongly suggests that organic compound of low polarity play an important role in the acute toxicity to the ciliated epithelium. In the methanol group, which is a solvent that has the ability of extract organic compound of intermediate polarity, resulting in a proportional increase in the low and high polarity compounds, we observed a significant increase in the proportional volume of acid mucus when compared to controls. A higher proportional volume of acid mucus denotes a shift in the intracellular mucins to a more acidic profile, which in turn is closely associated to epithelial damage (Lemos et al., 1994; Pires-Neto et al., 2006; Yoshizaki et al., 2010).

Corroborating this finding, in the hexane group, which is a solvent that extracts mainly organic compound of low polarity, we did not found significant differences in all parameters of histological analysis and also in MCT relative time and ciliary beating frequency, when compared to control group. Removing organic compound of low polarity resulted in a similar pattern of the frog-ringer treated group. Laks et al. (2008) found that in mice exposition to DEPA fractions treated with hexane, promoted a similar pattern to the saline control group, when evaluating pulmonary dynamics and the degree of neutrophil infiltration in pulmonary parenchyma.

In DEPF - Study II, the proportional volume of acid mucus comparison between control and intact DEPA did not present significant differences. Besides this unexpected finding, this result is coherent with the MCT relative time, as we also did not find differences in this parameter.

Nitric acid treatment, which is a solvent that removes inorganic fraction, eliciting a proportional increase in the organic fraction as a whole, promoted a significant decrease in the neutral mucus amount, when compared to hexane group. Once again, our findings demonstrate that increasing organic fraction proportional volume disrupted epithelium integrity by promoting physicochemical alterations in intracellular mucins, closely correlated with epithelial damage.

Our study has some limitations and strengths. The DEPA dilutions concentrations used are higher than usually found in the urban environment atmosphere. Although it is not possible to extrapolate any given concentration in a liquid system to the air environment, we aimed at working with high concentrations of intact DEPA, in order to highlight the effects of an acute exposition to high concentrations of DEPA.

One could argue that the phase I findings were a result of the osmotic or other properties of the dilutions itself, rather than the chemical interference exerted by DEPA. Our phase II findings showed that dilutions with the same concentration, but with different chemical composition, presented very different response patterns. In this scenario, we eliminated the "dilution concentration effect", and the only difference was chemical compounds.

In summary, our Dose Response Curve Study shows that even an acute exposition to high concentrations of DEPA is able to disrupt the integrity of mucociliary apparatus and change significantly the chemical profile of intra-epithelial mucins, along with structural changes of the pseudo-stratified ciliated epithelium of the frog palate. In Diesel Exhaust Particles Fractions Study, organic compound of low polarity, seems to play a pivotal role in the acute toxicity to the ciliated epithelium. The molecular mechanism and cell signaling responsible for mucociliary clearance disruption and acidification of intra-epithelial mucus still require further investigation.

\section{Conclusions}

The Dose Response Curve Study revealed that increasing concentrations of DEPA can progressively impair mucociliary clearance and promote a shift in the chemical profile of the intra-epithelial mucus eliciting acidification of mucus associated to depletion of neutral mucins. DEPA seem to act as secretagogue promoting mucus extrusion and consequently reducing epithelial thickness.

In Diesel Exhaust Particles Fractions Study, our results suggest that DEPA organic fraction of low polarity play an important role in the acute toxicity to the ciliated epithelium, by promoting acidification in the intracellular mucins associated to a disruption in mucociliary transport integrity.

\section{Acknowledgements}

FAPESP (2011/50334-7) and CNPq (2008/57717-6).

\section{Conflict of interests}

The authors declare no conflicts of interest.

\section{Appendix A. Supporting information}

Supplementary data associated with this article can be found in the online version at http://dx.doi.org/10.1016/j.ecoenv.2017.10.041.

\section{References}

Braga, P.C., Allegra, L., King, M., 1973. Mathematically analysis of dynamic measures. In: Gabelnick, H.L., Litt, M. (Eds.), Rheology of Biological Systems. Springfield, Thomas, pp. 119-157.

Carvalho-Oliveira, R., Saiki, M., Pires-Neto, R.C., Lorenzi-Filho, G., Macchione, M., Saldiva, P.H., 2005. Anti-oxidants reduce the acute adverse effects of residual oil fly ash on the frog palate mucociliary epithelium. Environ. Res. 98, 349-354.

Daviskas, E., Anderson, S.D.J., 2006. Hyperosmolar agents and clearance of mucus in the diseased airway. Aerosol Med. Spring 19 (1), 100-109.

Dockery, D.W., Pope 3rd, C.A., Xu, X., Spengler, J.D., Ware, J.H., Fay, M.E., et al., 1993. An association between air pollution and mortality in six US. cities. N. Engl. J. Med. 329, 1753-1759.

Filleul, L., Rondeau, V., Vandentorren, S., Le Moual, N., Cantagrel, A., Annesi-Maesano, I., et al., 2005. Twenty five year mortality and air pollution: results from the French PAARC survey. Occup. Environ. Med. 62, 453-460.

Forastiere, F., Stafoggia, M., Picciotto, S., Bellander, T., D'Ippoliti, D., Lanki, T., et al., 2005. A case-crossover analysis of out-of-hospital coronary deaths and air pollution in Rome, Italy. Am. J. Respir. Crit. Care Med. 172, 1549-1555.

Giddens, W.E., Fairchild, G.A., 1972. Effects of sulfur dioxide on the nasal mucosa of mice. Arch. Environ. Health 25, 166-172.

Goldberg, M.S., Burnett, R.T., Yale, J.F., Valois, M.F., Brook, J.R., 2006. Associations between ambient air pollution and daily mortality among persons with diabetes and cardiovascular disease. Environ. Res. 100, 255-267.

Hiura, T.S., Kazubowsky, M.P., Li, N., Nel, A.E., 1999. Chemicals in diesel exhaust particles generate reactive oxygen radicals and induce apoptosis in macrophages. J. Imunnol. 163, 5582-5591.

Holma, B., 1989. Effects of inhaled acids on airway mucus and its consequences for health. Environ. Health Perspect. 79, 109-113.

Holma, B., Lindegren, M., Morkholdt Anderson, J., 1977. pH effects on ciliomotility and morphology of respiratory mucosa. Arch. Environ. Health 32, 216-226.

Kato, A., Kagawa, J., 2003. Morphological effects in rat lungs exposed to urban roadside air. Inhal. Toxicol. 15, 799-818.

Laks, D., Oliveira, R.C., André, P.A., Macchione, M., Lemos, M., Faffe, D., et al., 2008. Composition of diesel particles influences acute pulmonary toxicity: an experimental study in mice. Inhal. Toxicol. 20 (11), 1037-1042.

Lemos, M., Lichtenfelds, A.J., Amaro Júnior, E., Macchione, M., Martins, M.A., King, M., et al., 1994. Quantitative pathology of nasal passages in rats exposed urban levels of air pollution. Environ. Res. 66, 87-95.

Li, N., Wang, M., Oberley, T.D., Sempf, J.M., Nel, A.E., 2002. Comparison of pro-oxidative and proinflammatory effects of organic diesel exhaust particle chemical in bronchial epithelial cells and macrophages. J. Imunnol. 169, 4531-4541.

Li, R., Meng, Z., Xie, J., 2007. Effects of sulfur dioxide on the expressions of MUC5AC and ICAM-1 in airway of asthmatic rats. Regul. Toxicol. Pharmacol. 48 (3), 284-291.

Macchione, M., Guimarães, E.T., Saldiva, P.H., Lorenzi-Filho, G., 1995. Methods for studying respiratory mucus and mucus clearance. Braz. J. Med. Biol. Res. 28, 1347-1355.

Macchione, M., Oliveira, A.P., Gallafrio, C.T., Muchão, F.P., Obara, M.T., Guimarães, E.T., et al., 1999. Acute effects of inhalable particles on the frog palate mucociliary epithelium. Environ. Health Prespect. 107, 829-833.

Martins, L.C., Latorre, M.R., Cardoso, M.R., Gonçalves, F.L., Saldiva, P.H., Braga, A.L 2002. Poluição atmosférica e atendimentos por pneumonia e gripe em São Paulo, Brasil. Rev. Saúde Pública 36, 88-94.

Miraglia, S.G.E.K., Saldiva, P.H.N., Böhm, G.M., 2005. An evaluation of air pollution health impacts and costs in São Paulo, Brazil. Environ. Manag. 35 (5), 667-676.

Neutra, M.R., Forstner, J.F., 1987. Gastrointestinal mucus: synthesis, secretion, and function. In: Johnson., L.R. (Ed.), Proceedings of the Gastrointestinal Tract. Raven, New York, pp. 975-1009. 
Pires-Neto, R.C., Lichtenfels, A.J., Soares, S.R., Macchione, M., Saldiva, P.H., Dolhnikoff, M., 2006. Effects of São Paulo air pollution on the upper airways of mice. Environ. Res. 101, 356-361.

Prent $\varnothing$, P., 2009. Staining of macromolecules: possible mechanisms and examples. Biotech. Histochem. 84, 139-158.

Rose, M.C., Voynow, J.A., 2006. Respiratory tract mucin genes and mucin glycoproteins in health and disease. Physiol. Rev. 86 (1), 245-278.

Rubin, B.K., Ramirez, O., King, M., 1990b. Mucus-depleted frog palate as a model for the study of the mucociliary clearance. J. Appl. Physiol. 69, 424-429.

Rubin, B.K., Ramirez, O., Finegan, B., King, M., 1990a. Analysis of airway mucus collected from healthy subjects at the time of surgery. Am. Rev. Respir. Dis. 141, 1040-1043.

Seriani, R., Junqueira, M.D.S., de Toledo, A.C., Martins, M.A., Seckler, M., Alencar, A.M., Macchione, M., 2014. Diesel exhaust particulates affect cell signaling, mucin profiles, and apoptosis in trachea explants of Balb/C mice. Environ. Toxicol. 30 (11), 1297-1308.

Seriani, R., Junqueira, M.S., Carvalho-Sousa, C.E., Arruda, A.C., Martinez, D., Alencar, A.M., Garippo, A.L., Brito, J. Martins, M.A, Saldiva, P.H.N. Negri, Mauad, E.M., T. Macchione, M., 2015a. Enriched inorganic compounds in diesel exhaust particles induce mitogen-activated protein kinase activation, cytoskeleton instability, and cytotoxicity in human bronchial epithelial cells. Exp. Toxicol. Pathol. 67 (4), 323-329.

Seriani, R., Junqueira, M.S., Toledo, A.C., Corrêa, A.T., Silva, L.F., Martins, M.A., Macchione, M., 2015b. Organic and inorganic fractions of diesel exhaust particles produce changes in mucin profile of mouse trachea explants. J. Toxicol. Environ. Health, Part A 78 (4), 215-225.

Seriani, R., de Souza, C.E.C., Krempel, P.G., Frias, D.P., Matsuda, M., Correia, A.T., Mauad, T...., Macchione, M., 2016. Human bronchial epithelial cells exposed in vitro to diesel exhaust particles exhibit alterations in cell rheology and cytotoxicity associated with decrease in antioxidant defenses and imbalance in pro-and anti-apoptotic gene expression. Environ. Sci. Pollut. Res. 23 (10), 9862-9870.

Souza, M.B., Saldiva, P.H., Pope 3rd, C.A., 1998. Respiratory changes due to long-term exposure to urban levels of air pollution: a histopathologic study in humans. Chest $113,1312-1318$.

Yoshizaki, K., Brito, J.M., Toledo, A.C., Nakagawa, N.K., Piccin, V.S., Junqueira, M.S. et al., 2010. Subchronic effects of nasally instilled diesel exhaust particulates on the nasal and airway epithelia in mice. Inhal. Toxicol. 22, 610-617. 